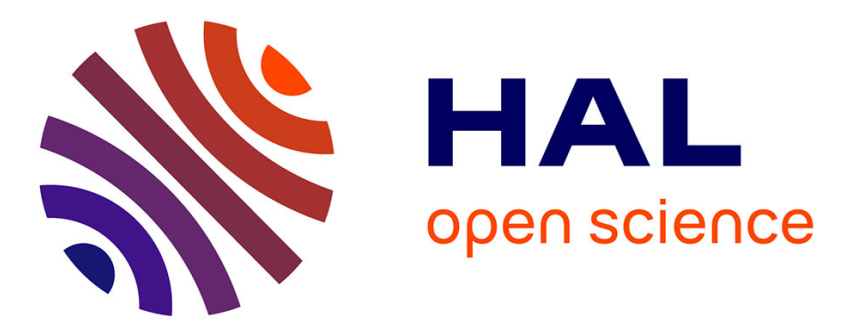

\title{
Solvent suppression in solid-state DNP NMR using Electronic Mixing-Mediated Annihilation (EMMA)
}

Fabio Ziarelli, Pierre Thureau, Stéphane Viel, Giulia Mollica

\section{To cite this version:}

Fabio Ziarelli, Pierre Thureau, Stéphane Viel, Giulia Mollica. Solvent suppression in solid-state DNP NMR using Electronic Mixing-Mediated Annihilation (EMMA). Magnetic Resonance in Chemistry, 2020, 10.1002/mrc.5001 . hal-02877099

\section{HAL Id: hal-02877099 \\ https://hal.science/hal-02877099}

Submitted on 22 Jun 2020

HAL is a multi-disciplinary open access archive for the deposit and dissemination of scientific research documents, whether they are published or not. The documents may come from teaching and research institutions in France or abroad, or from public or private research centers.
L'archive ouverte pluridisciplinaire HAL, est destinée au dépôt et à la diffusion de documents scientifiques de niveau recherche, publiés ou non, émanant des établissements d'enseignement et de recherche français ou étrangers, des laboratoires publics ou privés. 


\title{
Solvent suppression in solid-state DNP NMR using Electronic Mixing-Mediated Annihilation (EMMA)
}

\author{
Fabio Ziarelli, ${ }^{*}{ }^{*}$ Pierre Thureau, ${ }^{\dagger}$ Stéphane Viel ${ }^{\dagger}$ and Giulia Mollica ${ }^{* \dagger}$ \\ ${ }^{\dagger}$ Aix Marseille Univ, CNRS, ICR, Marseille, France \\ ๆInstitut Universitaire de France, Paris, France \\ \#Aix Marseille Univ, CNRS, Centrale Marseille, FSCM, Marseille, France
}

\section{Corresponding authors:}

fabio.ziarelli@univ-amu.fr, giulia.mollica@univ-amu.fr

\begin{abstract}
We show here that the Electronic Mixing-Mediated Annihilation (EMMA) method, previously reported for the suppression of background signals in solid-state NMR spectra, can be successfully applied to remove the solvent signals observed in the case of NMR spectra obtained with dynamic nuclear polarization (DNP). The methodology presented here is applied to two standard samplepreparation methods for DNP, namely glass forming and incipient wetness impregnation. It is demonstrated that the EMMA method is complementary to the different methods for solvent suppression based on relaxation filters, and that it can be used to preserve the quantitative information that might be present in the pristine spectra.
\end{abstract}

\section{Keywords}

Dynamic nuclear polarization; Solid-state NMR; Solvent suppression 


\section{Introduction}

High-field dynamic nuclear polarization (DNP) solid-state NMR can dramatically increase the strength of the NMR signal. ${ }^{1-11}$

DNP experiments usually rely on the polarization transfer from the electronic spin polarization to the nuclear spin. Consequently, in the case of diamagnetic insulating solids, an exogenous paramagnetic polarizing agent should be added to the sample under study. ${ }^{12-20}$ Sample preparation is thus key for valuable DNP solid-state NMR experiments.

Generally, a radical-containing solution is used to homogeneously distribute the polarizing agent throughout the sample under study. Unfortunately, a drawback of this sample preparation methodology is that the NMR signal(s) arising from the solvent will also be detected in the DNPenhanced solid-state NMR spectra, and they may overlap with NMR signals of interest. In the case of DNP-enhanced ${ }^{1} \mathrm{H}-{ }^{13} \mathrm{C} \mathrm{CP}$ MAS spectra, the use of deuterated organic solvents reduces the intensity of the resulting solvent NMR resonances, ${ }^{21}$ but this rarely proves sufficient. Interestingly, it is possible to suppress these unwanted solvent signals using different spectral filtering methods, such as relaxation filters ${ }^{22}$ dipolar dephasing ${ }^{23}$ or with the use of highly concentrated radicalcontaining solutions. ${ }^{24}$ These methods have proved useful, albeit limited to a specific class of sample preparation or instrumentation.

Here, we investigate the potential of the so-called Electronic Mixing-Mediated Annihilation (EMMA) method to suppress the unwanted solvent signals usually found in DNP-enhanced solidstate NMR spectra. In fact, we have shown previously that the EMMA method can be used to suppress background signals typically encountered in solid-state NMR spectra, such as those arising from the probe head components (e.g. stator, rotors, inserts). ${ }^{25}$ In this work, we show that EMMA can also be used to effectively suppress the solvent signals present when analyzing samples prepared by either glass forming ${ }^{26}$ or incipient wetness impregnation, ${ }^{27}$ two common sample-preparation methods used in DNP solid-state NMR, with clear advantages in terms of suppression efficiency with respect to relaxation-based spin-echo methods. 


\section{Material and methods}

\section{Sample preparation}

In this study, two distinct samples were considered. First, $5 \mathrm{mg}$ of a polystyrene- $b$-poly(ethylene oxide) block copolymer (PS- $b$-PEO) sample obtained by nitroxide-mediated polymerization, was impregnated with $25 \mu \mathrm{L}$ of a 1,1,2,2-tetrachloroethane (TCE) solution of TEKPol at $20 \mathrm{mM}$. The number-average molecular weight $\left(M_{\mathrm{n}}\right)$ of the PS and PEO blocks was 7000 and $1500 \mathrm{~g} \mathrm{~mol}^{-1}$, respectively. Before impregnation, the copolymer sample was finely ground by hand in a mortar and pestle for several minutes. The resulting impregnated pasty-like sample was mixed with a spatula and subsequently transferred into the sapphire $3.2 \mathrm{~mm}$ rotor (yielding a sample weight of $32 \mathrm{mg}$ inside the rotor). Second, a $250 \mathrm{mM}$ solution of ${ }^{13} \mathrm{C}$-enriched proline in a glycerol/ $\mathrm{H}_{2} \mathrm{O}$ $(60 / 40, v / v)$ mixture was prepared with AMUPol at $2 \mathrm{mM}$. We note that the amount of AMUPol was not optimized in this case to achieve the highest possible DNP signal enhancements. The solution was prepared in a $1.5 \mathrm{~mL}$ Eppendorf Tube ${ }^{\circledR}$ and then transferred with a pipette into a 3.2 $\mathrm{mm}$ rotor for analysis (sample weight of $26 \mathrm{mg}$ ). In all cases, no attempt was made to remove molecular oxygen from the samples even though this has been shown to increase NMR sensitivity, especially for PS-containing polymers. ${ }^{28}$

\section{NMR experiments}

All DNP solid-state NMR experiments were recorded on a Bruker 9.4 T wide-bore magnet (400 and $100 \mathrm{MHz}$ for the ${ }^{1} \mathrm{H}$ and ${ }^{13} \mathrm{C}$ Larmor frequency, respectively) operated by an AVANCE-III NMR spectrometer and equipped with a Bruker $3.2 \mathrm{~mm}$ low-temperature double-resonance DNP ${ }^{1} \mathrm{H} /{ }^{29} \mathrm{Si}_{-}{ }^{13} \mathrm{C}$ CP MAS probe head. The spectrometer was equipped with a gyrotron that allowed microwave $(\mu \mathrm{W})$ irradiation of the sample. Specifically, the field sweep coil of the NMR magnet was set so that $\mu \mathrm{W}$ irradiation occurred at the maximum DNP signal enhancement of TOTAPOL (263.334 GHz). The estimated power of the $\mu \mathrm{W}$ beam at the output of the probe head waveguide was $c a .4 \mathrm{~W}$. All DNP-enhanced solid-state NMR experiments were conducted with a MAS rate of $10 \mathrm{kHz}$ and at a temperature of $\sim 108 \mathrm{~K}$. The amplitude of the ${ }^{1} \mathrm{H}$ rf field was ramped during the contact time to improve CP efficiency. The recycle delay was $3.8 \mathrm{~s}$ and $20 \mathrm{~s}$ for the copolymer and proline samples, respectively, whereas the CP contact time was set to $1 \mathrm{~ms}$ in both cases. The 
experiments were recorded using a number of scans ranging between 1 and 16, with 4 dummy scans.

\section{EMMA method parameters}

In this study, two methods were tested to implement EMMA with comparable results. In a first implementation, a preliminary spectrum of the sample is acquired with a few scans only (typically between 1 and 4), and the signal to be removed is isolated using a simple spectral deconvolution. As many contributing Gaussian/Lorentzian signals (potentially mixed) can be used in the deconvolution process (with a broad variety of parameters in terms of frequency or linewidth) as long as the envelope due to the resonance(s) to be removed is faithfully reproduced. This differs from (and is facilitated with respect to) conventional deconvolution where the signals to be used must somehow relate to truly distinctive chemical environments. The resulting deconvoluted frequency spectrum can then be inverse Fourier transformed (iFT) to obtain the corresponding FID, which can be subsequently converted into a shaped pulse. The actual implementation of these particular operations may differ from one setup to another depending upon the type of processing software that is used. In our case, we used TopSpin ${ }^{\circledR}$ to do the iFT. This required us to generate a set of imaginary data points first (with a Hilbert transform launched by the $h t$ command in TopSpin $\left.{ }^{\circledR}\right)$ and then type ift in the Topspin command line. In doing so, it is important to respect the adequate number of data points (especially if one uses zero filling). Then, to generate the shaped pulse, we exported the resulting FID raw data as a text file (basically a list of real and imaginary data points) that was subsequently converted into a format readable by TopSpin ${ }^{\circledR}$ as a shape file (which requires transforming the list of real and imaginary data points into a list of complex numbers with their respective moduli and arguments). The so-obtained shaped pulse is then fed during FID acquisition via the directional coupler (without any $180^{\circ}$-phase shift at first) and its power is set so that the intensity of its frequency response in the NMR spectrum matches that of the signal(s) to be suppressed. Technically, the shaped pulse is used through a composite pulse-decoupling (CPD) program within the pulse sequence (which are both provided in supplementary information). Once this power has been properly adjusted, the EMMA spectrum can be recorded using the above-mentioned $180^{\circ}$-phase shift for actual signal cancellation. We note that the $180^{\circ}$ phase shift is inserted within the CPD program. In a second implementation, the shaped pulse can be obtained by analyzing under the same experimental conditions another similar 
sample that only contains the solvent without the analyte. In this case, the corresponding FID can be used directly to generate the shaped pulse without any deconvolution. This shaped pulse can be subsequently used to analyze the true sample under study using a procedure equivalent to that described above.

\section{Results and Discussion}

The EMMA method relies on the use of an electronically digitized signal (i.e. a shaped pulse) that matches the frequency, shape, width and intensity of the signal to be suppressed. During acquisition of the FID, this signal is fed directly into the receiver coil via a directional coupler (Figure 1) with a $180^{\circ}$-phase shift, leading to the cancellation of the undesired signals (herein, the solvent signals).

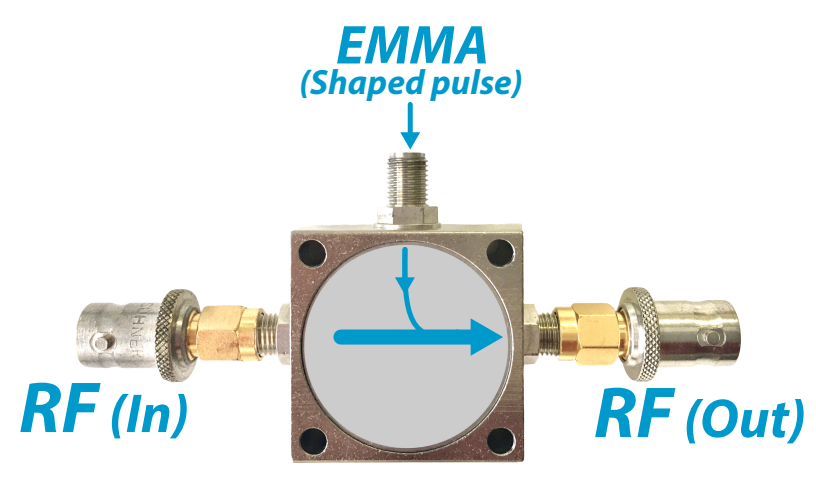

Figure 1. Picture of the directional coupler used in this study to add the electronically digitized signal directly into the NMR receiver coil during FID acquisition.

As a first example, Figure 2a shows the DNP-enhanced ${ }^{1} \mathrm{H}-{ }^{13} \mathrm{C}$ CP MAS spectrum for a polystyrene- $b$-poly(ethylene oxide) block copolymer (PS- $b$-PEO) impregnated with a 1,1,2,2tetrachloroethane (TCE) solution of TEKPol at $20 \mathrm{mM}$. In this case, we observe that the TCE signal partially overlaps with the PEO resonance at $c a .65 \mathrm{ppm}$. This spectrum was used to generate the shaped pulse required for EMMA by deconvoluting the $60 \mathrm{ppm}-80 \mathrm{ppm}$ spectral region in order to extract the spectral contribution due to TCE. The power of the shaped pulse was then adjusted to match the intensity of the TCE signal (see experimental section for details), and then the resulting shaped pulse was $180^{\circ}$-phase shifted prior to being injected in the NMR receiver coil (via the simple directional coupler shown in Figure 1) during the acquisition of the FID. Alternatively, the shaped pulse could also be generated by analyzing a similar TCE solution but 
without any copolymer using the resulting FID as an input to create the adequate shaped pulse (vide infra). As can be seen in Figure 2b, this leads to the (almost) complete annihilation of the TCE signal in the DNP-enhanced ${ }^{1} \mathrm{H}-{ }^{13} \mathrm{C}$ CP MAS spectrum of the sample, where the ${ }^{13} \mathrm{C}$ resonance due to the PEO moiety of the PS- $b$-PEO copolymer can now be clearly identified.

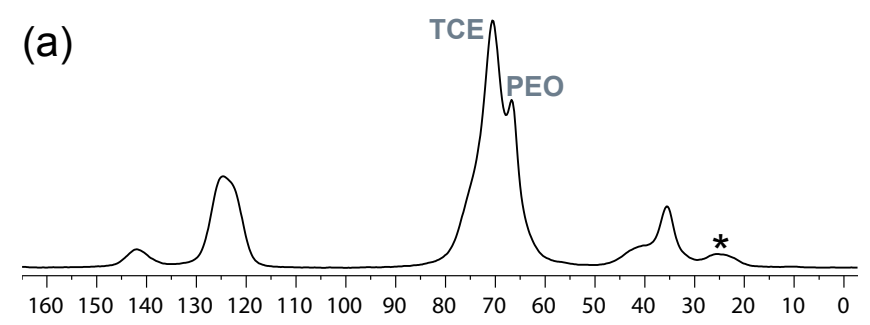

(b)

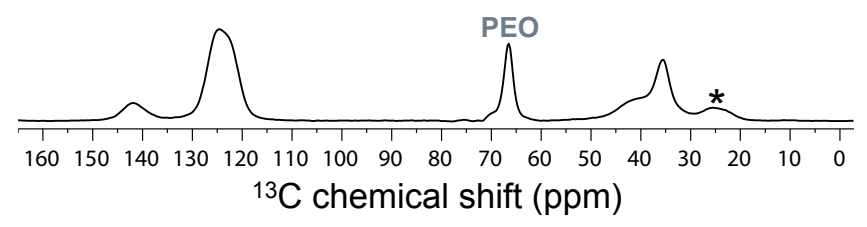

Figure 2: DNP-enhanced ${ }^{1} \mathrm{H}-{ }^{13} \mathrm{C} C \mathrm{CP}$ MAS spectra of a polystyrene- $b$-poly(ethylene oxide) block copolymer (PS- $b$-PEO) impregnated with a 1,1,2,2-tetrachloroethane (TCE) solution of TEKPol at $20 \mathrm{mM}$. Both spectra were recorded with microwave irradiation and at a temperature of $108 \mathrm{~K}$. In (a) the signals due to TCE and to the PEO moiety of the PS- $b$-PEO copolymer partially overlap. In (b) the TCE signal has been cancelled out by the EMMA method, hence revealing the PEO resonance. The other resonances in the spectrum are due to the aromatic and aliphatic carbons of the PS moiety, whereas spinning side bands are evidenced with a "*”.

Interestingly, the quality of the suppression achieved with EMMA can also be observed in Figure 3 where the same DNP-enhanced ${ }^{1} \mathrm{H}-{ }^{13} \mathrm{C} C \mathrm{CP}$ MAS spectra (acquired with and without EMMA) are compared to the spectrum obtained with a spin-echo ( $\left.T_{2}{ }^{\prime}\right)$ filter (using an echo time of $3.2 \mathrm{~ms}$ ). As can be seen, the quality of the signal suppression obtained in both cases for the TCE resonance is comparable, but this is accompanied for the spin-echo filtered spectrum by a significant loss in intensity for the PS and PEO resonances (whereas the corresponding resonances are untouched in the spectrum acquired with EMMA). Moreover, the relative loss between the PS and PEO signals is not comparable (the latter being more attenuated than the former as a result of shorter $T_{2}^{\prime}$ values), which rules out the possibility of using such data for any meaningful quantitative analysis. As a matter of fact, the integrals in the spectrum shown in Figure $2 b$ match the expected relative weight proportion for the PEO and PS blocks. 


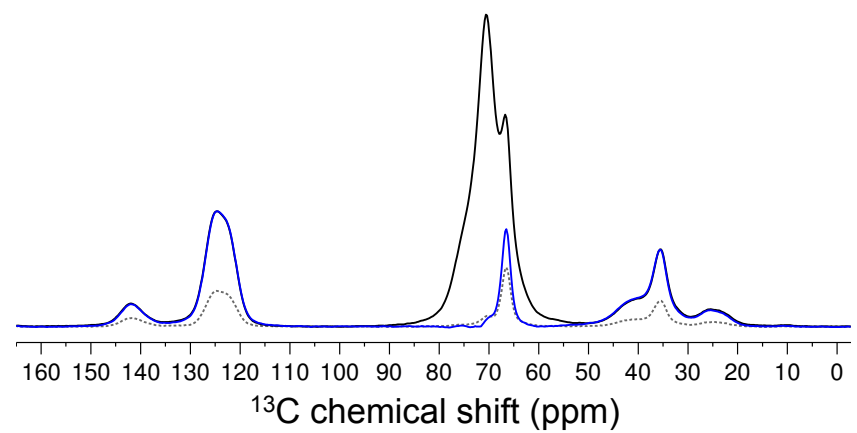

Figure 3: Comparison of the DNP-enhanced ${ }^{1} \mathrm{H}_{-}{ }^{13} \mathrm{C}$ CP MAS spectrum of the TCE-impregnated PS- $b$-PEO block copolymer sample (black line) with the corresponding ${ }^{1} \mathrm{H}-{ }^{13} \mathrm{C} \mathrm{CP}$ MAS spectra recorded with EMMA (blue line) and with a spin-echo filter (dashed grey line). The black and blue lines almost perfectly overlap except for the $80 \mathrm{ppm}-60 \mathrm{ppm}$ spectral region where the TCE resonance has been fully suppressed by EMMA. In contrast, achieving comparable signal suppression with the spin-echo filter requires the use of a rather long echo time $(3.2 \mathrm{~ms})$, which leads to the loss in signal intensity for the resonances due to the PS and PEO moieties of the block copolymer.

An additional example of the EMMA methods is shown in Figure 4a with the DNP-enhanced ${ }^{1} \mathrm{H}-{ }^{13} \mathrm{C}$ CP MAS spectrum of a $250 \mathrm{mM}{ }^{13} \mathrm{C}$-enriched proline solution in a glycerol/ $\mathrm{H}_{2} \mathrm{O}(60 / 40$, v/v) mixture containing the DNP polarizing agent AMUPol. ${ }^{14}$ The signal corresponding to the $\mathrm{CH}_{2}$ groups of glycerol at $57 \mathrm{ppm}$ strongly overlaps with the signal due to the $\mathrm{CH}$ group of proline. In this case, the EMMA shaped pulse was generated by analyzing a similar glycerol/water mixture but without proline (see experimental section). The resulting FID was used as an input to create the shaped pulse whose power was subsequently adjusted to match the intensity of the glycerol spectral contribution (using the $\mathrm{CH}$ group resonance at $68 \mathrm{ppm}$ as a guide). The so-obtained EMMA pulse was eventually injected in the NMR receiver coil during FID acquisition with a $180^{\circ}$-phase shift. As can be seen in Figure 4b, this leads to the (almost) complete annihilation of the glycerol signals in the DNP-enhanced ${ }^{1} \mathrm{H}-{ }^{13} \mathrm{C}$ CP MAS spectrum of the sample, and all ${ }^{13} \mathrm{C}$ signals of proline can now be clearly identified (see the inset of Figure $4 \mathrm{a}$ for molecular assignment). Interestingly, comparison of the integrals for the signal areas at $55.2 \mathrm{ppm}$ (proline $\mathrm{CH}$ group), $41.8 \mathrm{ppm}$ (proline $\mathrm{NCH}_{2}$ group), and $23.7 \mathrm{ppm}$ (which includes the overlapping resonances at $25.5 \mathrm{ppm}$ and $20.7 \mathrm{ppm}$ due to the other $2 \mathrm{CH}_{2}$ groups of proline), shows that the expected relative proportion $(1: 1: 2)$ is nicely respected, which indicates that EMMA allows quantitative data to be obtained (provided of course that the NMR experiments are conducted under quantitative conditions in the first place). 

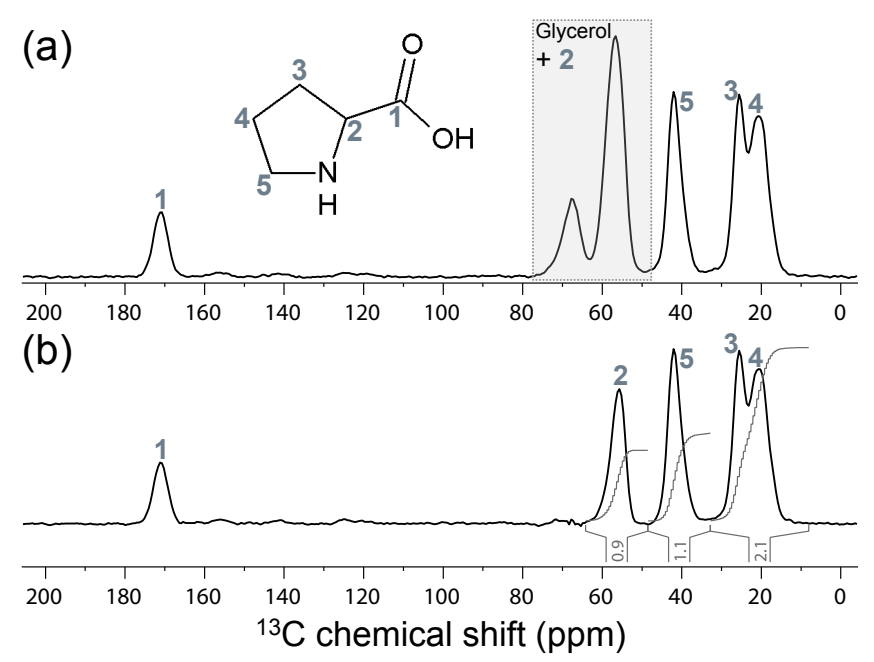

Figure 4. DNP-enhanced ${ }^{1} \mathrm{H}_{-}{ }^{13} \mathrm{C}$ CP MAS spectra of ${ }^{13} \mathrm{C}$-enriched proline dissolved at $250 \mathrm{mM}$ in a glycerol $/ \mathrm{H}_{2} \mathrm{O}(60 / 40, \mathrm{v} / \mathrm{v})$ solution containing the DNP polarizing agent AMUPol at $2 \mathrm{mM}$ (note that no attempt was made to optimize the DNP signal enhancement in this case). Both spectra were recorded with microwave irradiation and at a temperature of $108 \mathrm{~K}$. In (a) the signal due to the $\mathrm{CH}$ group of proline found at $57 \mathrm{ppm}$ strongly overlaps with the signal due to the $\mathrm{CH}_{2}$ groups of glycerol, whereas in (b) the solvent signals (due to the $\mathrm{CH}$ and $\mathrm{CH}_{2}$ groups of glycerol) have been cancelled by the EMMA method.

\section{Conclusion}

This work shows that the EMMA method can suppress the unwanted signals of the two main solvents used in the case of DNP-enhanced CP MAS experiments, i.e. glycerol and TCE. Therefore, the presented methodology is appropriate for the investigation of a wide range of sample preparations. Contrary to existing methodologies, the EMMA method does not require a triple-channel probe (although it does require a triple-channel spectrometer). Furthermore, contrary to solvent suppression methods based on relaxation filters, the EMMA method does not suffer from sensitivity penalty or is limited to a single preparation method, and it retains the quantitative character of the NMR data. Therefore, the EMMA method is expected to be especially beneficial for the observation of signals corresponding to diluted species, which might disappear as a result of the application of relaxation-based solvent suppression approaches.

\section{Acknowledgement}

We thank Bruker SAS for access to the solid-state NMR spectrometer used here and Dr F. Aussenac and Dr P. Dorffer for experimental assistance. This study has received funding from the Excellence Initiative of Aix-Marseille University - A*Midex, a French "Investissements 
d'Avenir" programme supported of the A*MIDEX project (no. ANR-11-IDEX-0001-02) funded by the "Investissements d'Avenir", and from the European Research Council (ERC) under the European Union's Horizon 2020 research and innovation programme (grant agreement No 758498).

\section{References}

1. Hall, D. A.; Maus, D. C.; Gerfen, G. J.; Inati, S. J.; Becerra, L. R.; Dahlquist, F. W.; Griffin, R. G., Polarization-Enhanced NMR Spectroscopy of Biomolecules in Frozen Solution. Science 1997, 276 (5314), 930.

2. Ni, Q. Z.; Daviso, E.; Can, T. V.; Markhasin, E.; Jawla, S. K.; Swager, T. M.; Temkin, R. J.; Herzfeld, J.; Griffin, R. G., High Frequency Dynamic Nuclear Polarization. Acc. Chem. Res. 2013, 46 (9), 1933-1941.

3. Rossini, A. J.; Zagdoun, A.; Lelli, M.; Lesage, A.; Copéret, C.; Emsley, L., Dynamic Nuclear Polarization Surface Enhanced NMR Spectroscopy. Acc. Chem. Res. 2013, 46 (9), 19421951.

4. Lee, D.; Hediger, S.; De Paëpe, G., Is solid-state NMR enhanced by dynamic nuclear polarization? Solid State Nucl. Magn. Reson. 2015, 66-67, 6-20.

5. Lilly Thankamony, A. S.; Wittmann, J. J.; Kaushik, M.; Corzilius, B., Dynamic Nuclear Polarization for Sensitivity Enhancement in Modern Solid-state NMR. Prog. Nucl. Magn. Reson. Spectros. 2017, 102-103, 120-195.

6. Rossini, A. J., Materials Characterization by Dynamic Nuclear Polarization-Enhanced Solid-State NMR Spectroscopy. J. Phys. Chem. Lett. 2018, 9 (17), 5150-5159.

7. Perras, F. A.; Kobayashi, T.; Pruski, M., Growing Signals from the Noise: Challenging Nuclei in Materials DNP. In eMagRes, 2018; Vol. 7, pp 35-50.

8. Plainchont, B.; Berruyer, P.; Dumez, J.-N.; Jannin, S.; Giraudeau, P., Dynamic Nuclear Polarization Opens New Perspectives for NMR Spectroscopy in Analytical Chemistry. Anal. Chem. 2018, 90 (6), 3639-3650.

9. Rankin, A. G. M.; Trébosc, J.; Pourpoint, F.; Amoureux, J.-P.; Lafon, O., Recent developments in MAS DNP-NMR of materials. Solid State Nucl. Magn. Reson. 2019, 101, 116143.

10. Equbal, A.; Li, Y.; Leavesley, A.; Huang, S.; Rajca, S.; Rajca, A.; Han, S., Truncated Cross Effect Dynamic Nuclear Polarization: An Overhauser Effect Doppelgänger. J. Phys. Chem. Lett. 2018, 9 (9), 2175-2180. 
11. Mollica, G.; Ziarelli, F.; Thureau, P.; Viel, S., Chapter 22 Structural Investigations of Polymer Materials by Dynamic Nuclear Polarisation Solid-state NMR. In NMR Methods for Characterization of Synthetic and Natural Polymers, The Royal Society of Chemistry: 2019; pp 533-554.

12. Kiesewetter, M. K.; Corzilius, B.; Smith, A. A.; Griffin, R. G.; Swager, T. M., Dynamic Nuclear Polarization with a Water-Soluble Rigid Biradical. J. Am. Chem. Soc. 2012, 134 (10), 4537-4540.

13. Mathies, G.; Caporini, M. A.; Michaelis, V. K.; Liu, Y.; Hu, K.-N.; Mance, D.; Zweier, J. L.; Rosay, M.; Baldus, M.; Griffin, R. G., Efficient Dynamic Nuclear Polarization at $800 \mathrm{MHz} / 527 \mathrm{GHz}$ with Trityl-Nitroxide Biradicals. Angew. Chem. Int. Ed. 2015, 54 (40), $11770-11774$.

14. Sauvée, C.; Rosay, M.; Casano, G.; Aussenac, F.; Weber, R. T.; Ouari, O.; Tordo, P., Highly Efficient, Water-Soluble Polarizing Agents for Dynamic Nuclear Polarization at High Frequency. Angew. Chem. Int. Ed. 2013, 52 (41), 10858-10861.

15. Wisser, D.; Karthikeyan, G.; Lund, A.; Casano, G.; Karoui, H.; Yulikov, M.; Menzildjian, G.; Pinon, A. C.; Purea, A.; Engelke, F.; Chaudhari, S. R.; Kubicki, D.; Rossini, A. J.; Moroz, I. B.; Gajan, D.; Copéret, C.; Jeschke, G.; Lelli, M.; Emsley, L.; Lesage, A.; Ouari, O., BDPA-Nitroxide Biradicals Tailored for Efficient Dynamic Nuclear Polarization Enhanced Solid-State NMR at Magnetic Fields up to 21.1 T. J. Am. Chem. Soc. 2018, 140 (41), 13340-13349.

16. Mentink-Vigier, F.; Marin-Montesinos, I.; Jagtap, A. P.; Halbritter, T.; van Tol, J.; Hediger, S.; Lee, D.; Sigurdsson, S. T.; De Paëpe, G., Computationally Assisted Design of Polarizing Agents for Dynamic Nuclear Polarization Enhanced NMR: The AsymPol Family. $J$. Am. Chem. Soc. 2018, 140 (35), 11013-11019.

17. Geiger, M.-A.; Jagtap, A. P.; Kaushik, M.; Sun,H.; Stöppler, D.; Sigurdsson, S. T.; Corzilius, B.; Oschkinat, H., Efficiency of Water-Soluble Nitroxide Biradicals for Dynamic Nuclear Polarization in Rotating Solids at 9.4 T: bcTol-M and cyolyl-TOTAPOL as New Polarizing Agents. Chem. Eur. J. 2018, 24 (51), 13485-13494.

18. Bothe, S.; Nowag, J.; Klimavičius, V.; Hoffmann, M.; Troitskaya, T. I.; Amosov, E. V.; Tormyshev, V. M.; Kirilyuk, I.; Taratayko, A.; Kuzhelev, A.; Parkhomenko, D.; Bagryanskaya, E.; Gutmann, T.; Buntkowsky, G., Novel Biradicals for Direct Excitation Highfield Dynamic Nuclear Polarization. J. Phys. Chem. C 2018, 122 (21), 11422-11432.

19. Vioglio, P. C.; Thureau, P.; Juramy, M.; Ziarelli, F.; Viel, S.; Williams, P. A.; Hughes, C. E.; Harris, K. D. M.; Mollica, G., A Strategy for Probing the Evolution of Crystallization Processes by Low-Temperature Solid-State NMR and Dynamic Nuclear Polarization. J. Phys. Chem. Lett. 2019, 10 (7), 1505-1510. 
20. Ouari, O.; Phan, T.; Ziarelli, F.; Casano,G.; Aussenac, F.; Thureau, P.; Gigmes, D.; Tordo, P.; Viel, S., Improved Structural Elucidation of Synthetic Polymers by Dynamic Nuclear Polarization Solid-State NMR Spectroscopy. ACS Macro Lett. 2013, 2 (8), 715-719.

21. Le, D.; Casano, G.; Phan, T. N. T.; Ziarelli, F.; Ouari, O.; Aussenac, F.; Thureau, P.; Mollica, G.; Gigmes, D.; Tordo, P.; Viel, S., Optimizing Sample Preparation Methods for Dynamic Nuclear Polarization Solid-state NMR of Synthetic Polymers. Macromolecules 2014, 47 (12), 3909-3916.

22. Yarava, J. R.; Chaudhari, S. R.; Rossini, A. J.; Lesage, A.; Emsley, L., Solvent suppression in DNP enhanced solid state NMR. J. Magn. Reson. 2017, 277, 149-153.

23. Lee, D.; Chaudhari, S. R.; De Paëpe, G., Solvent signal suppression for high-resolution MAS-DNP. J. Magn. Reson. 2017, 278, 60-66.

24. Thureau, P.; Juramy, M.; Ziarelli, F.; Viel, S.; Mollica, G., Brute-force solvent suppression for DNP studies of powders at natural isotopic abundance. Solid State Nucl. Magn. Reson. 2019, 99, 15-19.

25. Mollica, G.; Ziarelli, F.; Tintaru, A.; Thureau, P.; Viel, S., Suppressing background signals in solid state NMR via the Electronic Mixing-Mediated Annihilation (EMMA) method. $J$. Magn. Reson. 2012, 218, 1-4.

26. Gerfen, G. J.; Becerra, L. R.; Hall, D. A.; Griffin, R. G.; Temkin, R. J.; Singel, D. J., High Frequency (140 GHz) Dynamic Nuclear Polarization: Polarization Transfer to a Solute in Frozen Aqueous Solution. J. Chem. Phys. 1995, 102 (24), 9494-9497.

27. Rossini, A. J.; Zagdoun, A.; Hegner, F.; Schwarzwälder, M.; Gajan, D.; Copéret, C.; Lesage, A.; Emsley, L., Dynamic Nuclear Polarization NMR Spectroscopy of Microcrystalline Solids. J. Am. Chem. Soc. 2012, 134 (40), 16899-16908.

28. Le, D.; Ziarelli, F.; Phan, T. N. T.; Mollica, G.; Thureau, P.; Aussenac, F.; Ouari, O.; Gigmes, D.; Tordo, P.; Viel, S., Up to 100\% Improvement in Dynamic Nuclear Polarization Solid-State NMR Sensitivity Enhancement of Polymers by Removing Oxygen. Macromolecular Rapid Communications 2015, 36 (15), 1416-1421. 


\section{List of Figures}

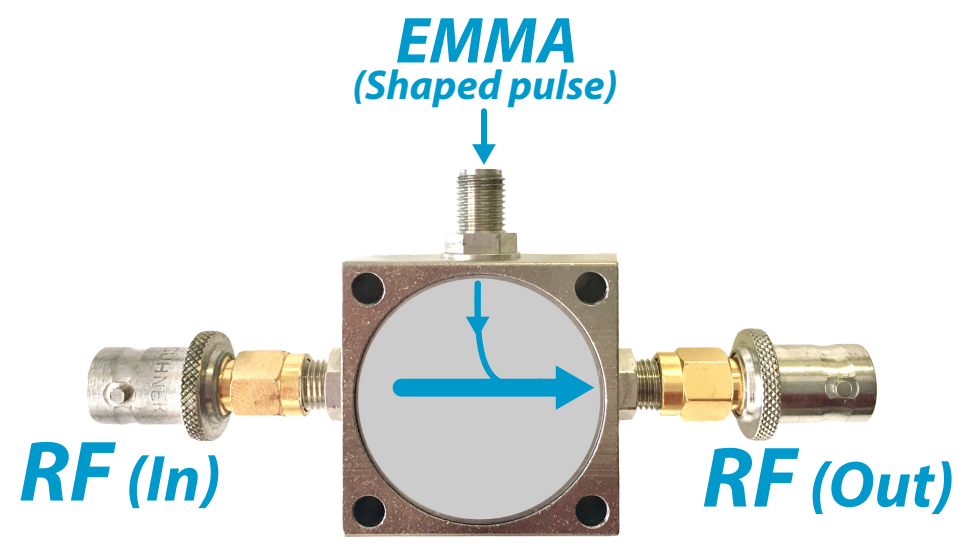

Figure 1. Picture of the directional coupler used in this study to add the electronically digitized signal directly into the NMR receiver coil during FID acquisition.

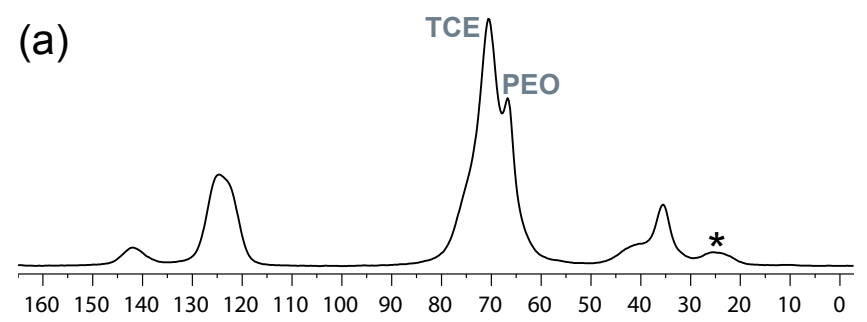

(b)

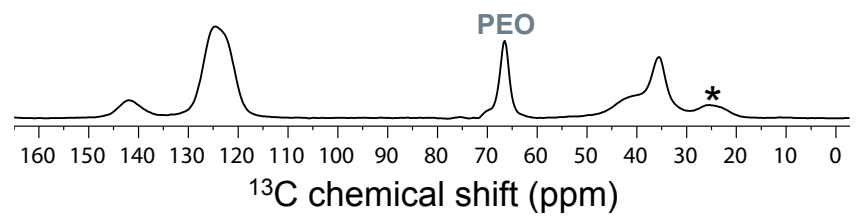

Figure 2: DNP-enhanced ${ }^{1} \mathrm{H}-{ }^{13} \mathrm{C} C P$ MAS spectra of a polystyrene- $b$-poly(ethylene oxide) block copolymer (PS- $b$-PEO) impregnated with a 1,1,2,2-tetrachloroethane (TCE) solution of TEKPol at $20 \mathrm{mM}$. Both spectra were recorded with microwave irradiation and at a temperature of $108 \mathrm{~K}$. In (a) the signals due to TCE and to the PEO moiety of the PS- $b$-PEO copolymer partially overlap. In (b) the TCE signal has been cancelled out by the EMMA method, hence revealing the PEO resonance. The other resonances in the spectrum are due to the aromatic and aliphatic carbons of the PS moiety, whereas spinning side bands are evidenced with a “*”. 


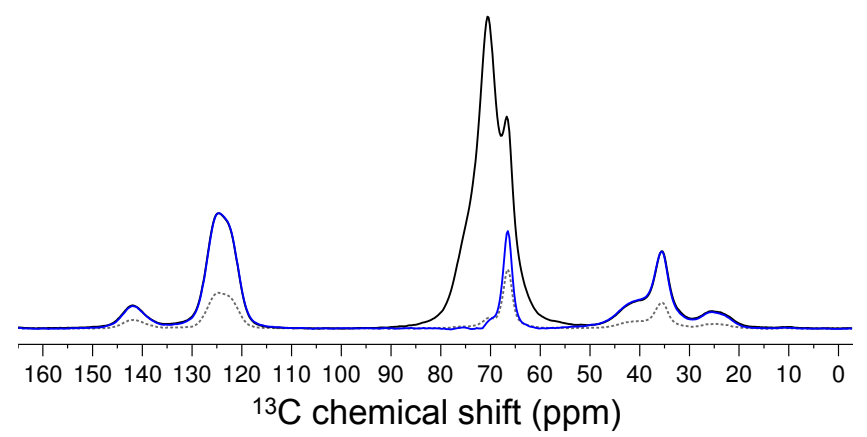

Figure 3: Comparison of the DNP-enhanced ${ }^{1} \mathrm{H}-{ }^{13} \mathrm{C} C P$ MAS spectrum of the TCE-impregnated PS- $b$-PEO block copolymer sample (black line) with the corresponding ${ }^{1} \mathrm{H}-{ }^{13} \mathrm{C} \mathrm{CP}$ MAS spectra recorded with EMMA (blue line) and with a spin-echo filter (dashed grey line). The black and blue lines almost perfectly overlap except for the $80 \mathrm{ppm}-60 \mathrm{ppm}$ spectral region where the TCE resonance has been fully suppressed by EMMA. In contrast, achieving comparable signal suppression with the spin-echo filter requires the use of a rather long echo time $(3.2 \mathrm{~ms})$, which leads to the loss in signal intensity for the resonances due to the PS and PEO moieties of the block copolymer.

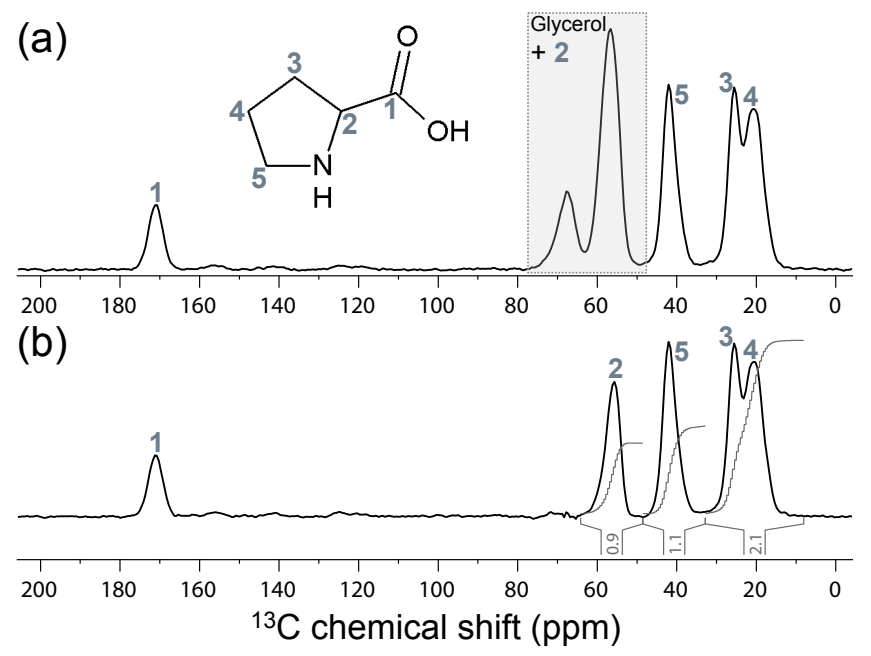

Figure 4. DNP-enhanced ${ }^{1} \mathrm{H}-{ }^{13} \mathrm{C}$ CP MAS spectra of ${ }^{13} \mathrm{C}$-enriched proline dissolved at $250 \mathrm{mM}$ in a glycerol $/ \mathrm{H}_{2} \mathrm{O}(60 / 40, \mathrm{v} / \mathrm{v})$ solution containing the DNP polarizing agent AMUPol at $2 \mathrm{mM}$ (note that no attempt was made to optimize the DNP signal enhancement in this case). Both spectra were recorded with microwave irradiation and at a temperature of $108 \mathrm{~K}$. In (a) the signal due to the $\mathrm{CH}$ group of proline found at $57 \mathrm{ppm}$ strongly overlaps with the signal due to the $\mathrm{CH}_{2}$ groups of glycerol, whereas in (b) the solvent signals (due to the $\mathrm{CH}$ and $\mathrm{CH}_{2}$ groups of glycerol) have been cancelled by the EMMA method. 
Graphical abstract: Fabio Ziarelli, Pierre Thureau, Stéphane Viel and Giulia Mollica "Solvent suppression in solid-state DNP NMR using Electronic Mixing-Mediated Annihilation (EMMA)"

\section{Solvent Suppression in MAS DNP by}

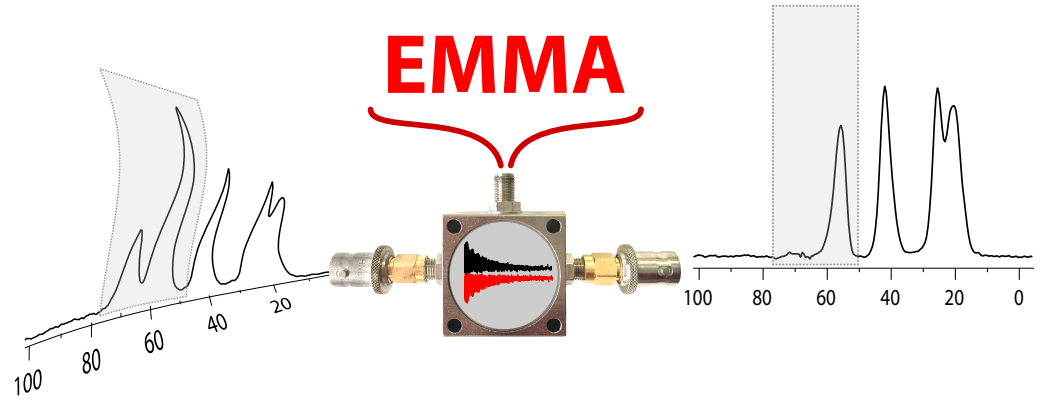

Electronic Mixing-Mediated Annihilation (EMMA) method can be successfully applied to remove the solvent signals observed in the case of NMR spectra obtained with dynamic nuclear polarization (DNP). The methodology is demonstrated on two standard sample-preparation methods for DNP: glass forming and incipient wetness impregnation. EMMA method is complementary to other methods for solvent suppression based on relaxation filters and can preserve the quantitative character of the experiment. 